\title{
Flood estimation for a cloudburst event in an ungauged western himalayan catchment
}

\begin{abstract}
Cloud burst is one of the reasons of flash flood in hilly regions. Such events have caused heavy loss of life and property due to its devastating nature in terms of landslides and boulder movement along with shooting velocity of water which results in heavy change of momentum and hence the force. Often, these flash floods are associated with very small areal extent, less duration of storm and remoteness of location. It is difficult to predict the location and impact of cloud burst particularly when most of these hilly areas are ungauged. Therefore, such events sometime go unnoticed and even the events which are reported, have scanty data due to the poor ground monitoring mechanism. In India, there are 3 major states in North and 7 states in north-east which are termed as 'Himalayan states'. During the last few years, these states have experienced a number of cloud burst events which may be attributed to the increased anthropogenic activities and the climate change phenomena. Keeping this in mind, the present study aims at estimating the outflow flood hydrograph at the outlet of an unguaged Himalayan catchment using Synthetic Unit Hydrograph. Some of the historical cloudburst events in Northern Himalaya are studied and accordingly the runoff and basin lag corrections are suggested. The results are compared with the previous study reported in literature. Such study is expected to help in disaster preparedness. Further, it highlights the need for comprehensive data base of such events over the entire Himalayan range for effective disaster management in the region.
\end{abstract}

Keywords: cloudburst, flash flood, snyder's method
Volume I Issue $6-2017$

Kansal Mitthan Lal K,Thakur Avinash

Department of Water Resources Development \& Management,

Indian Institute of Technology Roorkee, India

Correspondence: Kansal ML, Department of Water Resources Development \& Management, Indian Institute of Technology Roorkee, India, Email mlkgkfwt@iitr.ac.in

Received: August 19,2017| Published: November 27, 2017

\section{Introduction}

Cloud burst is one of the reasons of flash flood in hilly regions. Such events are devastating as these induce landslides and boulder movement along with shooting velocity of water in hilly areas. This results in huge change of momentum and hence the large force. This force along with flood movement causes heavy loss of life and property. Cloudburst is a sudden aggressive rainstorm of small duration (few minutes to few hours) with rainfall intensity of more than $100 \mathrm{~mm} / \mathrm{hr} .{ }^{1}$ Some of the extreme rainfall events recorded in India range from $900 \mathrm{~mm} /$ day to $1,040 \mathrm{~mm} /$ day. $^{2}$ In India, there are 3 major states (Jammu and Kashmir, Himachal Pradesh, and Uttarakhand) in North and 7 states Assam, Arunachal Pradesh, Manipur, Meghalaya, Mizoram, Nagaland and Tripura) in north-east which are termed as 'Himalayan states'. During the last few years, these states have experienced a number of cloudburst events. Cloudbursts in Himalayan region represent the rapid convective lifting of moist air mass under the conditions of steep orography and thermodynamic instability. The warm and humid air moves uphill due to orography of the area. As this air mass continues to rise up, it forms large clouds. Lack of upper air at such great heights prevents the dissipation and water concentration in the cloud keeps on increasing which finally result in sudden localized downpour of water (Figure 1). Generally, cloud-burst is a localized weather phenomena concentrated over a small area (not exceeding 20-30 $\mathrm{km}^{2}$ ). Researchers have attributed the cloud burst phenomena to the increased anthropogenic activities and the climate change. Generally, it occurs in the rainy (monsoon) season (June to September). Often, these events are associated with very small areal extent, less duration of storm and remoteness of location. It is difficult to predict the location and impact of cloud burst particularly when most of these hilly areas are ungauged. Therefore, such events sometime go unnoticed and even the events which are reported, have scanty data due to the poor ground monitoring mechanism or sometimes even these also get washed away. Only data which remain available for such events is the flood water scars on the banks of streams, uprooted trees, and visual observations by the local people. These large number of eye witnesses provide crucial and reasonably accurate information of flood timing. ${ }^{3}$ Some of the recent cloud burst events occurred in the state of Uttarakhand in India and their estimated impact are as follows:

i. July 6, 2004 - At least 17 people found dead and 28 injured when three vehicles swept in the Alaknanda River due to heavy landslides triggered by a cloudburst. This event stranded about 5000 pilgrims near Badrinath shrine area in Chamoli district.

ii. August 7, 2009 - 38 people were found dead due to landslide resulting from a cloudburst in Nachni area near Munsiyari in Pithoragarh district.

iii. August 5, 2010- A cloudburst was reported in Leh region of Jammu and Kashmir. The flash floods affected 52 villages in the area, covering about 1,420 hectares of land and completely destroyed 1,749 houses.

iv. September 15, 2010 - A cloud burst in Almora completely drowned the two villages leaving only a few people alive.

v. September 14, 2012 - Rudraprayag district experienced a cloudburst which resulted in death of 39 people.

vi. June 17, 2013 - A cloudburst in Kedarnath and Rambada region 
in Kedar valley occurred which was termed as 'Tsunami of Himalaya'. Over 10000 people were found dead and more than 100,000 got affected.

vii. On September 6, 2014- A cloudburst occurred in Kashmir valley killing more than 200 people. Center for Science and Environment (CSE) mentioned heavy and unchecked development aggravated the development in the region.

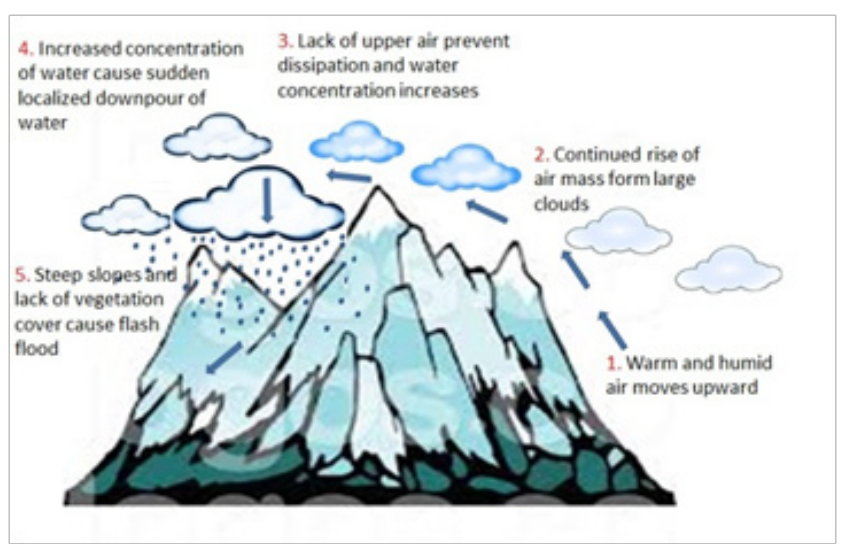

Figure I Schematic diagram of cloudburst and flash flood generation.

Keeping the importance of cloud burst in mind and its role in flash flood, it is desired to assess the quantum of flood caused by such an event in an unguaged catchment. This study focuses on Synthetic Unit Hydrograph approach for the north Himalayan regions of India. The suggested approach is validated through one of the cloud burst event. In future the proposed methodology can be extended to other regions and its reliability can be improved with availability of more data.

\section{Study area}

India has been classified in seven hydro-meteorological homogenous zones with different sub-zones. The Western Himalayan belt falls under zone 7 (Figure 2). This covers the states of Uttarakhand, Himachal Pradesh and Jammu \& Kashmir. There is very less of no vegetation in such areas to offer resistance to flow. Also the land surface in these catchments generally has less infiltration index. So the flood hydrographs for these catchments are generally high peaked and narrow with very less time of peak. In this study, Leh cloudburst (2010) has been discussed and obtained results for the same have been compared with results of Renoj et al. ${ }^{4}$ Leh is a small town in Ladhakh region of the state of Jammu and Kashmir. Ladhakh covers $52.6 \%$ area of state of Jammu and Kashmir ${ }^{4}$ and shares India's northern boundary with Pakistan and China. The area has a long history of glaciations, and every subsequent glaciations in the region was smaller than the previous one. ${ }^{5}$ Due to adverse climatic conditions in the region, the settlements are sparsely situated. District Leh is situated roughly between 32 to 36 degree north latitude and 75 to 80 degree East longitude and altitude ranging from $2300 \mathrm{~m}$ to 5000 $\mathrm{m}$ above sea level. District Leh with an area of $45,100 \mathrm{~km}^{2}$ makes it $2^{\text {nd }}$ largest district in the country after Kutch (Gujrat) with an area 45,652 $\mathrm{km}^{2}$ in terms of area. The district is bounded by Pakistan occupied Kashmir in the west and china in the north and eastern part and Lahul Spiti of Himachal Pradesh in the south east. Ladhakh lies on the rain shadow side of the Himalayan, where dry monsoon winds reaches Leh after being robbed of its moisture in plains and the Himalayas mountain the district combines the condition of both arctic and desert climate. Therefore Ladhakh is often called "COLD DESERT". There is a wide diurnal and seasonal fluctuation in temperature with $-40^{\circ} \mathrm{C}$ in winter and $+35^{\circ} \mathrm{C}$ in summer. Precipitation in this region is very low with annual precipitation of $10 \mathrm{~cm}$ mainly in form of snow. Air is very dry and relative humidity range from $6-24 \%{ }^{6}$

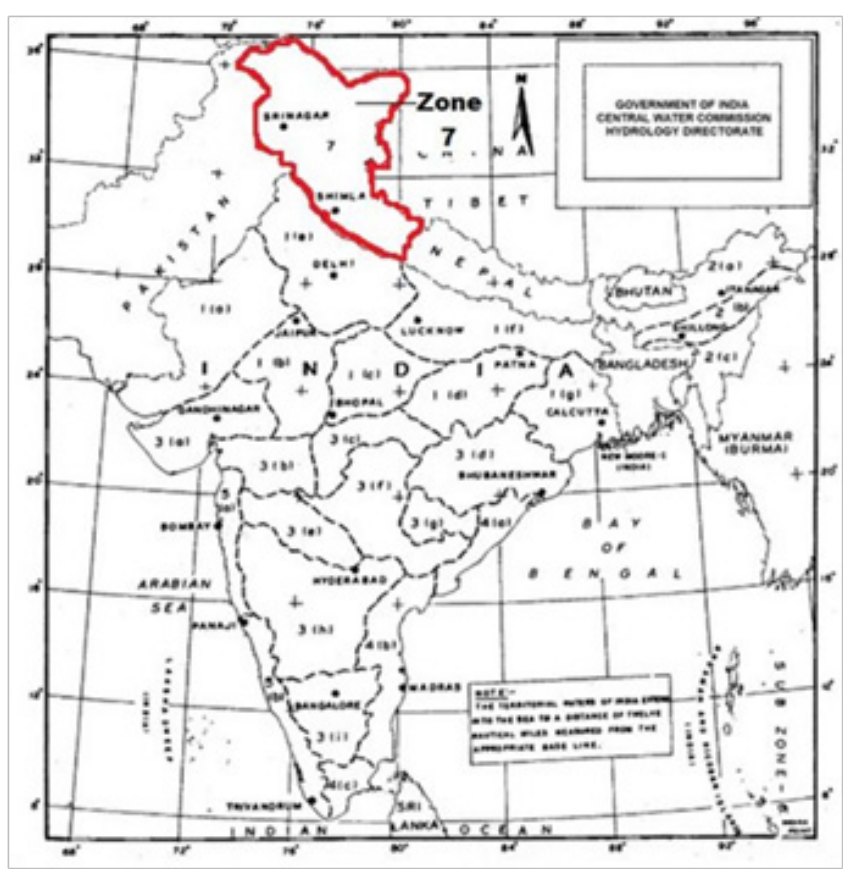

Figure 2 Western Himalayan States. ${ }^{7}$

\section{Methodology}

Quantum of flood in a catchment can be assessed in terms of peak, peak time and the time distribution of flow in terms of flood hydrograph. Flood estimation can be studied under following categories of methods:

\section{Empirical.}

2. Rational.

3. Flood frequency analysis.

4. Unit hydrograph.

Empirical method uses regional formulae based on correlation between discharge and catchment characteristics. Almost all the empirical formulae represent discharge as a function of catchment area. These formulae are regionally valid and give approximate results when applied to other catchments. For example, Dicken's formula [7] is widely used in India as the first approximate value of peak flood in a catchment, which is given as:

$$
Q_{p}=C_{d} \cdot A^{\frac{3}{4}}
$$

\section{Where}

$\mathrm{Q}_{\mathrm{p}}$ : Peak discharge in cumec; $\mathrm{C}_{\mathrm{d}}$ : Varies from 6 to 30 (11.5 for northern India); A: Catchment area $\left(\mathrm{km}^{2}\right)$

Rational method another semi-empirical formula used for peak 
flood estimation in small catchments. It considers a rainfall of uniform intensity occurring over small catchments such that duration of rainfall is greater than the time of concentration for catchment. Runoff is assumed to increase gradually to a peak value at the time of concentration or time of peak and stay at the peak as long as the rainfall continues. Mathematically, flood peak and peak time (Kirpich equation) are represented as:

$$
\begin{aligned}
& Q_{p}=\frac{1}{3.6} C\left(i_{c p}\right) A \\
& t_{c}=t_{p}=0.01947 L^{0.77} S^{-0.385}
\end{aligned}
$$

\section{Where}

\section{C: Coefficient of runoff: (runoff/rainfall);}

$\mathrm{i}_{\mathrm{cp}}$ : Mean intensity of precipitation $(\mathrm{mm} / \mathrm{h})$ for duration $\mathrm{t}_{\mathrm{c}}$.

In flood frequency method, one uses the observed maximum annual flow values and estimates the statistical parameters of the probability distribution. This information is for estimation of likelihood of flood as a function of recurrence interval. But as this method is based on historical data, it cannot be used in case of cloudburst event as there is very scanty or almost no historical data available for such events. A unit hydrograph represents the lumped response of catchment to a unit rainfall excess of D-h duration to produce direct runoff hydrograph. The factors that affect the shape of unit hydrograph have been studied under two groups i.e. physiographic factors and storm characteristics. Physiographic factors include basin characteristics (shape, size, slope, nature of the valley, drainage density, elevation etc.), infiltration characteristics (land use and land cover, lakes and other storages, soil type and geological conditions) and channel characteristics (crosssections, roughness, storage capacity etc.). Storm characteristics include precipitation, intensity, duration, magnitude and movement of storm. The effect of various factors on hydrograph is as follow: The shape of basin influence the time of concentration i.e. the time taken for water from the remotest part of catchment to reach the outlet. Fan shaped catchments gives high peak and narrow hydrographs while elongated catchments give narrow peaked and broad hydrographs. Size of a basin affects its behaviour. In small catchments channel flows are predominant by overland flows. Hence intensity of rainfall and land use has greater impact on peak flood. In larger catchments channel flow is more predominant. Time base for larger catchments will be larger as compare to corresponding hydrographs for smaller catchments. Slope of the stream controls the velocity of flow in channel. Slope has significant effect on recession limb of hydrograph as it represents the depletion of storage. The basin slope for smaller catchments is more important where overland flow is predominant. Steeper slopes result in larger peak discharges. Ratio of total channel length to total drainage area is known as drainage density. Large drainage density results in quick conduction of water down the channel that reflects as pronounced peak discharge. In basins with small drainage densities, the overland flow is more predominant and hence the resulting hydrograph is squat with a slowly rising limb. Vegetal cover offers resistance to the flow of water and increases the infiltration and storage capacities of soil. This results in reduced peak of hydrograph. This effect is very pronounced for catchments with smaller areas. Intensity, duration and direction of storm movement are the most important climatic factors that affect the shape of a flood hydrograph. Peak and volume of surface runoff are directly proportional to intensity of rainfall for a given duration. Duration of a storm of given intensity also has direct proportional effect on volume of runoff. There will be quicker concentration of flow if a storm moves from upstream end of catchment to downstream end. This results in high peak flood. This effect is further attenuated by shape of catchments. Hydrographs for long and narrow catchments are most sensitive to direction of storm movements. Detailed information about rainfall and resulting flood hydrographs is not available for all catchments, especially in remote and small catchments. To construct unit hydrographs for such catchments empirical relationships of regional validity has been given by a number of researchers. ${ }^{8}$ A number of methods are reported in literature for developing synthetic hydrographs. But these methods being based on empirical relationships have regional limitations and they should not be considered as general relationships for all regions. Central Water Commission (CWC) has classified India in seven hydrometeorologically homogenous zones. Each zone is described by a different set of relationships for the synthetic unit hydrograph. For example, western Himalayan region lies in the zone 7. However, the recommended synthetic unit hydrograph is only useful for catchment area greater than $25 \mathrm{~km}^{2} .{ }^{9}$ Therefore, it cannot be used for derivation of unit hydrograph for cloudburst events as it is a localized and restricted to area less than $25 \mathrm{~km}^{2}$. Snyder (1938) developed a set of empirical equations for synthetic unit hydrograph based on the study for a large number of catchments in USA. These equations are as follow:

$$
\begin{aligned}
& t_{p}=C_{t}\left(L L_{c a}\right)^{0.33} \\
& t_{r}=\frac{t_{p}}{5.5} \\
& Q_{p s}=\frac{2.78 C_{p} A}{t_{p}} \\
& t_{p}{ }^{\prime}=t_{p}+\frac{t_{R}-t_{r}}{4} \\
& Q_{p}=\frac{2.78 C_{p} A}{t_{p}} \\
& T_{b}=5\left(t_{p}{ }^{\prime}+\frac{t_{R}}{2}\right) \\
& W_{50}=\frac{5.87}{q^{1.08}}
\end{aligned}
$$

Where

$$
\begin{gathered}
q=\frac{Q_{p}}{A} \\
W_{75}=\frac{W_{50}}{1.75}
\end{gathered}
$$

\section{Where}

$t_{p}$, Basin lag In hour; L: Basin length measured along the water course from basin divide to gauging station in $\mathrm{km} ; \mathrm{L}_{\mathrm{ca}}$, Distance along the main water course from the gauging station to a point opposite to watershed centroid in $\mathrm{km}$; $\mathrm{C}$, A regional constant representing watershed slopes and storage effects; $t_{r}$, Standard duration of effective rainfall; $\mathrm{Q}_{\mathrm{ps}}$, Peak discharge for unit hydrograph of standard duration; 
$\mathrm{C}_{\mathrm{p}}$, A regional coefficient; $\mathrm{t}_{\mathrm{R}}$, Actual duration of effective rainfall; $\mathrm{Q}_{\mathrm{p}}$, Peak discharge for actual unit hydrograph; $\mathrm{t}_{\mathrm{p}}$ ': Basin lag in hour for effective rainfall of $t_{R}$ hour; $T_{b}$, Base time; $W_{50}$, Width of unit hydrograph at $50 \%$ peak discharge; $\mathrm{W}_{75}$, Width of unit hydrograph at $75 \%$ peak discharge.

Value of $C_{t}$ in Snyder's study ranged from 1.35 to 1.65 but many other studies have shown that its value depends on the region under study. Wide variation in the value of $C_{t}(0.3-6.0)$ has been reported. Value of $\mathrm{C}_{\mathrm{p}}$ is considered to be a representation of retention and storage capacity of catchment and ranges from 0.56 to 0.69 for Snyder's study. But depending on the region under study these coefficient may have values outside these ranges also. Linsley et al. ${ }^{10}$ have suggested modified formula for basin lag as:

$$
t_{p}=C_{t l}\left(\frac{L L_{c a}}{\sqrt{S}}\right)^{n}
$$

Where,

$\mathrm{S}$ : Basin slope; $\mathrm{C}_{\mathrm{t}}$, Basin constant; $\mathrm{n}$ : Regional constant ( 0.38 for study of catchments in USA).

US Soil Conservation services (SCS) has suggested equation to estimate the value of peak discharge $Q_{p}$ and time of peak $T_{p}$ which is very popular method used in watershed development activities especially in small catchments. The equations that are developed based on the study of large no of catchments are as follow:

$$
\begin{aligned}
& t_{p}=0.6 t_{c} \\
& T_{p}=\left(0.6 t_{c}+\frac{t_{r}}{2}\right) \\
& Q_{p}=2.98 \frac{\mathrm{A}}{t_{p}} \\
& T_{b}=2.67 T_{p}
\end{aligned}
$$

\section{Where}

$t_{c}$ : Time of concentration; $t_{r}$ : Duration of effective rainfall; $t_{p}$ : Lag time; $T_{p}$ : Time of peak; $Q_{p}:$ Peak discharge in cumecs; A: Area of catchment in $\mathrm{km}^{2}$

SCS dimensionless unit hydrograph facilitates the construction of unit hydrograph. In this ordinate is $\mathrm{Q} / \mathrm{Q}_{\mathrm{p}}$ that is the discharge $\mathrm{Q}$ expressed as the ratio to peak discharge $Q_{p}$ and the abscissa is $t / t_{p}$ which is the time $t$ expressed as the ratio of time to peak $t_{p}$ (Table 1). This unit hydrograph has same percentage of volume on rising side as the SCS triangular unit hydrograph. Since most of the Himalayan catchments facing cloudbursts are very remote and of smaller areal extent, they are generally unguaged. There is no single recommended method for flood estimation of such events. Therefore, in this study, applicability of these methods is examined for the assessment of flood hydrograph and its characteristics by using empirical, Rational, Snyder's Synthetic Unit Hydrograph and SCS method. Various coefficients that represent the catchment characteristics in these methods are based on normal conditions before the occurrence of a storm. However, in case of cloudburst, generally the soil is fully saturated and depressions are already full. This causes a significant rise in the peak of outflow hydrograph and decreases the time of peak. Also, a major part of precipitation appears as surface runoff because the initial abstractions are very less. So the coefficients for runoff are higher as compare to those in normal cases. Further, considering steep slopes, small size of catchment, lack of vegetation, very small initial abstraction and saturation of soil make it imperative to select different coefficients. As a case study, cloud burst event which occurred in Leh ( $\mathrm{J} \& \mathrm{~K}$ State in north Himalaya) during night of $5^{\text {th }}$ August 2010. Gridded rainfall data of India Meteorological Department (IMD) suggested the storm intensity of $120 \mathrm{~mm} /$ day on $5^{\text {th }}$ August, 2010, whereas Kumar et al. ${ }^{11}$ suggest occurrence of 70 $\mathrm{mm}$ precipitation in $3 \mathrm{~h}$ on 5 th August. Area of catchment is about $0.842 \mathrm{~km} 2$ and length of main channel till the outlet of the catchment area is about $1.25 \mathrm{~km}$. This event is analysed by Renoj et al. ${ }^{4}$ This event is analysed by various methods in this study and is discussed as follows: Value of Dicken's coefficient for northern India is taken as 11.5. Considering this value, the peak flood for Leh catchment for unit rainfall is estimated to be $10.11 \mathrm{~m}^{3} / \mathrm{s}$. Attempt has been made to use the different values of runoff coefficient, slope and time of peak and the flood is estimated using Rational method. Further, in India, it is a recommended common practice to increase the peak flood by $25 \%$ for cloudburst event. The results are shown in Table 2. Characteristics of unit hydrograph using Snyder's SUH approach have been derived for different sets of $C_{t}$ and $C_{p}$ with $C_{t}$ ranging from 0.15 to 0.30 and $C_{p}$ ranging from 0.75 to 0.95 as shown in Table 3. SCS triangular Unit hydrograph method is used to estimate peak flood and peak time for the catchments and then the hydrograph (Figure 5) is constructed by SCS dimensionless unit hydrograph method using the peak food and base time. Same equation has been used for time of peak $\left(t_{p}\right)$ as given by Snyder's method. Peak flow is estimated to be $7.429 \mathrm{~m}^{3} \mathrm{~s} /$ and time of peak as $0.236 \mathrm{hrs}$. Base time for the hydrograph is estimated to be $1.28 \mathrm{hrs}$. The results obtained from above three methods are checked for the compliance with requirements of unit hydrograph and then compared with the results reported by Renoj et al. ${ }^{4}$ estimated by using atmospheric and hydrological modelling approach.

Table I Coordinates of SCS dimensionless unit hydrograph

\begin{tabular}{llll}
\hline $\mathbf{t} / \mathbf{T p}$ & $\mathbf{q} / \mathbf{Q p}$ & $\mathbf{t} / \mathbf{T p}$ & $\mathbf{q} / \mathbf{Q p}$ \\
\hline 0 & 0 & 1.4 & 0.75 \\
0.1 & 0.02 & 1.5 & 0.66 \\
0.2 & 0.08 & 1.6 & 0.56 \\
0.3 & 0.16 & 1.8 & 0.42 \\
0.4 & 0.28 & 2 & 0.32 \\
0.5 & 0.43 & 2.2 & 0.24 \\
0.6 & 0.6 & 2.4 & 0.18 \\
0.7 & 0.77 & 2.6 & 0.13 \\
0.8 & 0.89 & 2.8 & 0.1 \\
0.9 & 0.97 & 3 & 0.07 \\
1 & 1 & 3.5 & 0.04 \\
1.1 & 0.98 & 4 & 0.02 \\
1.2 & 0.92 & 4.5 & 0.01 \\
1.3 & 0.84 & 5 & 0
\end{tabular}


Table 2 Peak flood and time of peak for various values of runoff coefficient and slope estimated using rational method

\begin{tabular}{llll}
\hline Slope & Runoff & $\begin{array}{l}\text { tp } \\
\mathbf{h r}\end{array}$ & $\begin{array}{l}\text { Qp } \\
\mathbf{m}^{3} / \mathbf{s}\end{array}$ \\
\hline 0.1 & 0.85 & 0.25 & 4.98 \\
0.1 & 0.9 & 0.25 & 5.26 \\
0.1 & 0.95 & 0.25 & 5.55 \\
0.07 & 0.85 & 0.3 & 4.96 \\
0.07 & 0.9 & 0.3 & 5.26 \\
0.07 & 0.95 & 0.3 & 5.55 \\
0.05 & 0.85 & 0.33 & 4.98 \\
0.05 & 0.9 & 0.33 & 5.26 \\
0.05 & 0.95 & 0.33 & 5.55 \\
\hline
\end{tabular}

Table 3 Unit hydrograph characteristics for various values of $C_{t}$ and $C_{p}$

\begin{tabular}{lllll}
\hline Ct & Cp & Qp $\left(\mathrm{m}^{3} / \mathbf{s}\right)$ & tp hr & Tb $\mathbf{h r}$ \\
\hline 0.3 & 0.75 & 5.49 & 0.32 & 2.09 \\
0.3 & 0.8 & 5.86 & 0.32 & 2.09 \\
0.3 & 0.85 & 6.23 & 0.32 & 2.09 \\
0.3 & 0.9 & 6.59 & 0.32 & 2.09 \\
0.3 & 0.95 & 6.96 & 0.32 & 2.09 \\
0.25 & 0.75 & 6.4 & 0.28 & 1.87 \\
0.25 & 0.8 & 6.82 & 0.28 & 1.87 \\
0.25 & 0.85 & 7.23 & 0.28 & 1.87 \\
0.25 & 0.9 & 7.67 & 0.28 & 1.87 \\
0.25 & 0.95 & 8.1 & 0.28 & 1.87 \\
0.2 & 0.75 & 7.65 & 0.23 & 1.64 \\
0.2 & 0.8 & 8.16 & 0.23 & 1.64 \\
0.2 & 0.85 & 8.67 & 0.23 & 1.64 \\
0.2 & 0.9 & 9.18 & 0.23 & 1.64 \\
0.2 & 0.95 & 9.68 & 0.23 & 1.64 \\
0.15 & 0.75 & 9.51 & 0.19 & 1.42 \\
0.15 & 0.8 & 10.14 & 0.19 & 1.42 \\
0.15 & 0.85 & 10.78 & 0.19 & 1.42 \\
0.15 & 0.9 & 11.41 & 0.19 & 1.42 \\
0.15 & 0.95 & 12.04 & 0.19 & 1.42 \\
\hline & & & & \\
\hline
\end{tabular}

\section{Results}

Unit Hydrographs characteristics for different values of coefficients have been checked for compliance with basic requirements of unit hydrograph theory (Figure 3). Unit hydrograph obtained using SCS method and Snyder's method $\left(\mathrm{C}_{\mathrm{t}}=0.25, \mathrm{C}_{\mathrm{p}}=.85\right)$ have almost equal peak and also have same volume of runoff. Rational formula gives small peak as compare to other methods as well as estimated by Renoj et al. ${ }^{4}$ Therefore, it is recommended that flood hydrograph obtained by Snyder's method with $\mathrm{C}_{\mathrm{t}}=0.25$; and $\mathrm{C}_{\mathrm{p}}=0.85$ (Figure 4). However, one can also use the SCS method (Figure 5) as it is less data intensive with reasonable level of accuracy. The results of Snyder's $\left(\mathrm{C}_{\mathrm{t}}=0.25\right.$, $\mathrm{C}_{\mathrm{p}}=.85$ ) and SCS methods are compared with Renoj et al. ${ }^{4}$ (Table 4) and found to hold good considering the uncertainties involved in estimation ${ }^{12,13}$ Based on the identified parameters of the Snyder's and SCS approach, unit hydrograph characteristics for different size catchments have been assessed for 15 and 30 minutes storm durations as shown in Table 5 .

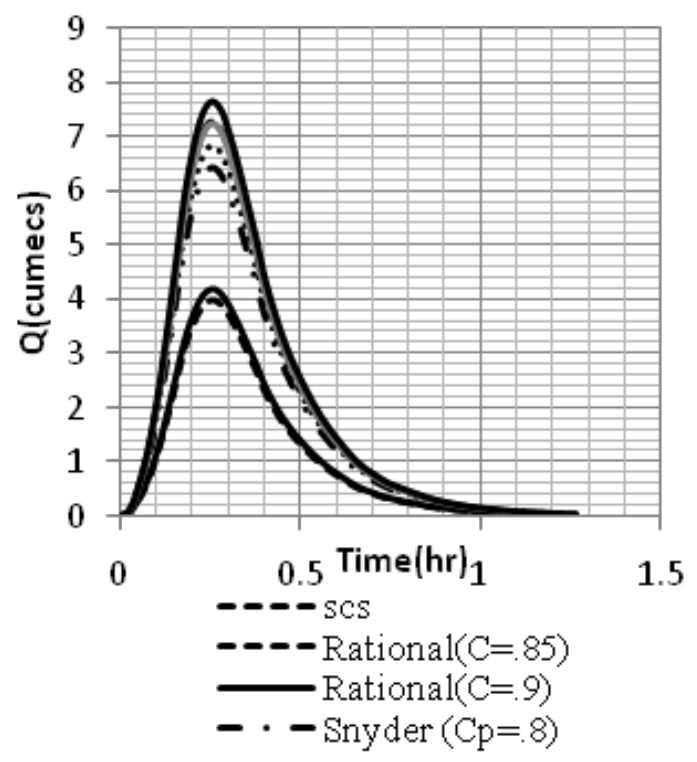

Figure 3 Unit hydrographs by different methods.

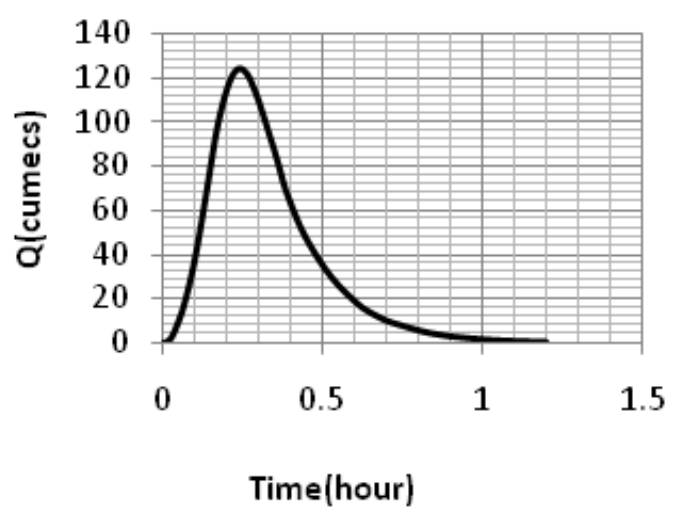

Figure 4 Flood hydrograph using Snyder's method.

Table 4 Comparison of flood hydrograph characteristics for Leh catchment estimated using different methods

\begin{tabular}{lllll}
\hline Method & Dicken's & Snyder & SCS & SCS* \\
\hline $\mathrm{tp}(\mathrm{hr})$ & - & 0.258 & 0.236 & - \\
$\mathrm{tb}(\mathrm{hr})$ & - & 1.87 & 1.28 & 0.92 \\
$\mathrm{Qp}\left(\mathrm{m}^{3} / \mathrm{s}\right)$ & 168.8 & 120.9 & 124.06 & 107 \\
\hline
\end{tabular}

SCS, Rennoj et al. ${ }^{4}$ 


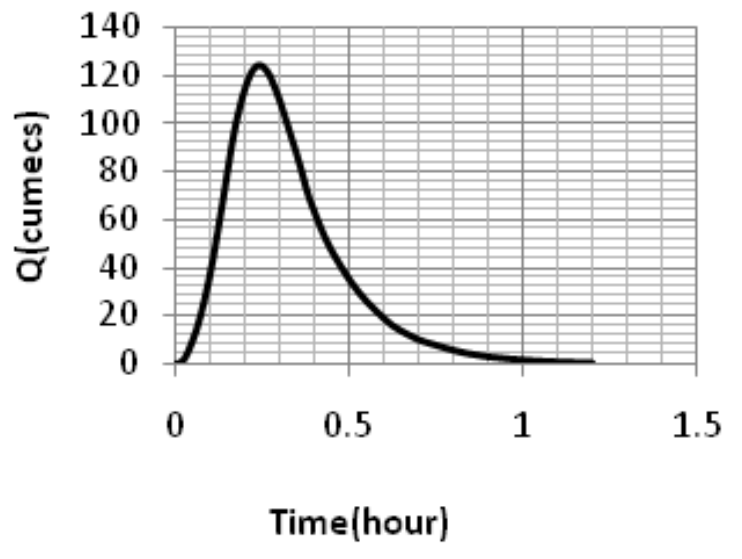

Figure 5 Flood hydrograph using SCS method.

Table 5 SUH characteristics by Snyder and SCS methods

\begin{tabular}{llllll}
\hline $\begin{array}{l}\text { Method } \\
\text { area }\left(\mathbf{k m}^{2}\right)\end{array}$ & $\begin{array}{l}\text { Duration } \\
\operatorname{tr}(\mathbf{h r})\end{array}$ & $\begin{array}{l}\text { Snyder } \\
\text { tp' (hr) }\end{array}$ & $\begin{array}{l}\text { Scs } \\
\mathbf{Q p}\left(\mathbf{m}^{3} / \mathbf{s}\right)\end{array}$ & tp & $\mathbf{Q p}\left(\mathbf{m}^{3} / \mathbf{s}\right)$ \\
\hline $\mathrm{I}$ & 0.5 & 0.34 & 6.82 & 0.23 & 8.96 \\
$\mathrm{I}$ & 0.25 & 0.28 & 8.32 & 0.23 & 8.96 \\
5 & 0.5 & 0.49 & 23.67 & 0.39 & 26.52 \\
5 & 0.25 & 0.43 & 27.05 & 0.39 & 26.52 \\
10 & 0.5 & 0.65 & 36.25 & 0.55 & 37.69 \\
10 & 0.25 & 0.58 & 40.1 & 0.55 & 37.69 \\
\hline
\end{tabular}

\section{Conclusion}

It is concluded that cloud burst contributes significantly in flood disasters particularly in hilly areas. Rational formula gives the underestimated values of peak flood whereas Dicken's method overestimates the same and both these methods provide peak flood value only. On the other hand flood estimation using techniques of unit-hydrograph for an ungauged catchment can help in estimating the temporal variation of cloud burst induced flood in hilly isolated areas. Further, results show that both SCS Triangular Unit Hydrograph method and Snyder's SUH method (for $\mathrm{C}_{\mathrm{t}}=0.25$ and $\mathrm{C}_{\mathrm{p}}=0.85$ ) can be used for peak flood estimation for cloudburst event in unguaged Himalayan catchments. However since Snyder's method takes into account more number of parameters and hence give more reliable results. So Snyder's method is suggested for estimation of flood hydrograph characteristics using corrected values of coefficients $\left(\mathrm{C}_{\mathrm{t}}=\right.$ 0.25 and $\mathrm{C}_{\mathrm{p}}=0.85$ ). SCS method may be used for rough estimations as it is easy and needs no adjustments. Further, there is need for comprehensive data base of such events over the entire Himalayan range for research work and hence effective disaster management in the region. ${ }^{14,15}$

\section{Acknowledgments}

None.

\section{Conflict of interest}

Authors declare there is no conflict of interest in publishing the article.

\section{References}

1. Das S, Ashrit R, Moncrieff MW. Moncrieff MW Simulation of a Himalayan cloudburst event. Journal of Earth System Science. 2006;115(3):299-313.

2. Dhar ON, Nandargi S. Rainfall magnitudes that have not been exceeded in India. Weather. 1998;53(5):145-151.

3. Gourley JJ, Erlingis JM, Smith TM, et al. Remote collection and analysis of witness reports on flash floods. Journal of Hydrology. 2010;394(1-2):53-62.

4. Renoj JT, Dimri AP, Pradeep K, et al. Study of cloudburst and flash floods around Leh, India, during; 2010August 4-6, Natural Hazards. 2012;65(3):2175-2204.

5. Owen LA, Caffee MW, Bovard KR, et al. Terrestrial cosmogenic nuclide surface exposure dating of the oldest glacial successions in the Himalayan orogeny: Ladakh Range, Northern India. GSA Bull. 2006;118(3-4):383-392.

6. LADHC Leh: Leh District Administration. 2015.

7. CWC. Estimation of Design Flood-Recommended Procedures, India; 1972.

8. Singh VP. Hydrologic systems: V.1. Rainfall-runoff modeling. PrenticeHall PTR, USA; 1988. p. 1-960.

9. CWC. Flood Estimation report for Western Himalayas- Zone7, India; 1994. p. $1-87$.

10. Linsley RK, Kohler Paulhus. Hydrology for Engineers, McGraw-Hill, USA; 1958.

11. Kumar MS, Shekhar MS, Rama KSSVS, et al. Numerical simulation of cloud burst event on August 05, 2010, over Leh using WRF mesoscale model. Natural Hazards. 2012;62(3):1261-1271.

12. Flaxman EM. Potential errors in peak discharge estimates obtained by indirect methods: Portland, Oregon, US Soil Conservation Service, USA; 1974. p. 1-15.

13. Jarret RD. Selected papers of the hydrological sciences: Evaluation of slope-area method for computing peak discharge. US Geological Survey Water Supply Paper 2310, USA; 1986. p. 1-141.

14. Dooge JCI. A general theory of the unit hydrograph. $J$ Geophys Res. 1959;64(2):241-256.

15. Tideman. Watershed Management: Guidelines for Indian Conditions, Omega Scientific Publishers, India; 2007. p. 1-13. 